\title{
Microgram per Milliliter
}

National Cancer Institute

\section{Source}

National Cancer Institute. Microgram per Milliliter. NCI Thesaurus. Code C64572.

A metric unit of mass concentration defined as the concentration of one gram of a substance per unit volume of the mixture equal to one cubic meter. The concept also refers to the metric unit of mass density (volumic mass) defined as the density of a substance which mass equal to one gram occupies the volume of one cubic meter. 